\title{
Individual, Household and Community-Level Effects of Infant and Child Mortality in Nigeria: A Logistic Regression Approach
}

\author{
Simeon Olawuwo ${ }^{1}$, N. Forcheh ${ }^{1} \&$ S. Setlhare ${ }^{1}$ \\ ${ }^{1}$ Department of Statistics, University of Botswana, Gaborone \\ Correspondence: Simeon Olawuwo, Department of Statistics, University of Botswana, Gaborone, Botswana.
}

Received: July 20, 2018 Accepted: August 24, 2018 Online Published: September 19, 2018

doi:10.5539/gjhs.v10n10p136 URL: https://doi.org/10.5539/gjhs.v10n10p136

\begin{abstract}
Research has shown that knowledge about the determinants of childhood mortality at the individual level is not enough to address the problem because the characteristics of the environment where a child is born tend to alter individual level characteristics and thereby affect child survival. The study used data from the 2013 Nigeria Demographic and Health Survey (NDHS). The fact that a child was either dead or alive was assumed to be accurately recorded. Hence, logistic regression model was used to model whether a child is dead or alive with respect to the selected predictor variables. Results from the study reveal that infant and child mortality in Nigeria is determined more by individual household than by community, and that geographical variations also exist. This study has identified significant risk factors that will help policy makers to formulate policies that will improve childhood survival.
\end{abstract}

Keywords: childhood mortality, logistic regression model, odd ratios, NDHS, individual-level factors

\section{Introduction}

Infant mortality is the deaths of young children, most especially those who are less than one year of age (Kayode et al., 2012). It is measured by the infant mortality rate (IMR). IMR was an indicator used to monitor progress towards the 4th Goal of the MDGs of the United Nations for the year 2015. It is now a target in the SDGs for Goal Number 3 (UNICEF, 2015). Taylor (Taylor, 2017) defined IMR as the number of deaths per 1,000 live births of children under one year of age. King and Zeng (King \& Zeng, 2001) noted that IMR is a useful indicator of the level of health or development of a country and is a component of the physical quality of life index. They opined that it reflects the socioeconomic development of a country and it essentially reveals the presence of good medical services in such country.

Child mortality, according to UNICEF (UNICEF, 2015), is defined as the death of children between the age of 1 year and 5 years. It is measured by child mortality rate (CMR). CMR is the probability of dying between the 1 st birthday and exactly 5 years of age. Unlike infant and under-five rates which are expressed per 1,000 live births, child mortality rate is expressed per children who survived infancy - i.e. up to 12 months (UNICEF, 2015). The proportion of child mortality in some developed nations is much lower than $1 \%$. Other countries - especially in Africa - still have high child mortality rates, but it's not true that these countries are not making progress (UNICEF, 2015).

Under-five mortality rate is considered as one of the most revealing measures of how well a society is meeting the needs of its people. West African countries experience infant and child mortality 2 to 3 times higher than the countries in southern Africa, and Nigeria is one of the major contributors to this negative statistic (UNICEF, 2012). Infant and child mortality rate in Nigeria is among the highest in the world (UNICEF, 2015). Although, recent analyses show that Nigeria is making progress in reducing these rates, but the pace is too slow (UNICEF, 2012). The 2013 NDHS estimated under-five mortality rate at 128 deaths per 1,000 live births compared to their counterpart in the UK which was said to be 2.8 children per 1,000 live births (Kayode et al., 2012). That is, 1 out of 8 children die before their 5 th birthday in Nigeria.

Addressing this problem demands a better understanding of the determinants and their contributions to high infant and child mortality in the country. Evidence from literature (Kayode et al., 2012) and (NPC, 2014) shows that knowledge about these determinants at just the child and mother level of characteristics is insufficient to address the problem. These studies found that incorporating region and community where a child is born tend to modify 
individual-level factors and therefore affect child survival. Hence even within the same country, the risk of death to a child is affected by the environment they were born into - whether it be an economically poor household, a marginalized community or a region frequently affected by conflicts. Such differences are prevalent across Nigeria.

As discussed in the NDHS report (NPC, 2014), extensive efforts were made to ensure that the death history data were as accurate as possible. However, descriptive summary of the data showed that the number of children reported to have died at 12 months was relatively too high as reported in the 2013 NDHS (NPC, 2014). A phenomenon described as age heaping at 12 months.

This likely error could lead to underestimation of infant mortality rate and over estimation of child mortality rate but should have no effect on overall under-five mortality rate. Since emphasis in this paper is to determine factors that explain variation in mortality rates rather than estimation of the rates per say, the effect of this error is expected to be minimal.

\subsection{Determinants of Infant and Child Mortality}

A number of studies have been conducted to find factors associated with infant and child mortality in many countries as well as in Nigeria (Houle et al., 2013) and (Kayode et al., 2012). From these studies, socio-economic, demographic, maternal and health care variables were found to have significant effects. The WHO (Tette et al., 2016) report showed that prominent among determinants of infant and child death in developing nations are poor source of drinking water, hygiene and indoor smoke from solid fuel. Feyisetan (Feyisetan, 1985) and Curtis et al. (Curtis et al., 2000) affirmed the contributions of these risk factors in their separate studies. Further, Olufunke and Obafemi (2011) argued that these children suffer the effect of unhealthy surroundings because they are always close to the ground, where many contaminants are contained. According to Feyisetan (Feyisetan, 1985), women from such unhealthy environment frequently expose themselves and their children to indoor air pollution as they spend many hours near open fire almost everyday cooking, with their children tied to their back. Mosley and Chen (1984) are among researchers who have found that that level of education of a mother can affect infant and child survival. Caldwell (1979) opined that education is the most important factor of infant and child survival. According to Caldwell (1979), an educated mother is more concerned about the health conditions of her child, more capable of getting attention from hospital workers and having more knowledge about where the right facilities are and how to best use them to the advantage of her child.

The 2013 NDHS (NPC, 2014) findings showed that $97 \%$ of women with more than a secondary education received antenatal care from a skilled provider, as compared with $36 \%$ of mothers who have no education. It is therefore expected that mothers with secondary education, compared to uneducated mothers, should have a better knowledge of the modern world and be able to use it to the survival advantage of their children.

To examine the influencing factors, logistic regression analysis has been used in some of the previous studies (Lawoyin, 2001) and (Houle et al., 2013). However, some of these studies did not examine certain covariates which may be very significant such as sanitation, immunization and breastfeeding in their research works which might have confounding effect. Consequently, it is important to discover the effects of these and many more because of the continual high rates of infant and child mortality in Nigeria. Using data from the 2013 NDHS, this study (1) examined the magnitudes of infant and child mortality in Nigeria; (2) developed a predictive model, using the logistic regression model to identify and examine the effects of individual, household and community-level factors on the risk of infant and child death. Because of almost one-to-one ratio between mother/child, mother/household, as revealed in the frequency distribution of these variables from the dataset, simple logistic regression is felt to be appropriate for the analysis at both the mother and child levels while multilevel logistic is considered appropriate at higher levels (cluster, state and region).

\section{Materials and Methods}

Full details of sample selection and data collection methods are discussed in (NPC, 2014). In the absence of a complete vital statistics and civil registration data for a given country, the DHS provides the best data estimating under-five mortality. The DHS has a further advantage over vital registration data because it includes data on all possible factors that could explain differential experience of death in different households, communities and regions.

As explained in (NPC, 2014), for the 2013 NDHS, data of interest were obtained from the survey, using 3 stage sampling procedure. In the first stage, each state was stratified into rural and urban localities and a sample of 893 localities selected with probability proportional to size. In stage 2, one enumeration areas (EAs) was randomly selected from each locality in most cases, and 2 EAs in a few cases where the locality was very large. This leads to 
904 second stage units (EAs). A within EA sampling frame consisting of all occupied households was constructed in each of the 904 selected EAs. If the EA had less than 80 occupied households then it was combined to an adjacent EA to form a single cluster. In the third and final stage, a single EA was randomly selected, equivalent to an EA with 80 or more households or two adjacent EAs with a combined population of least 80 households. A sample of 40,320 households in 904 clusters, with 45 households randomly selected from each cluster. All regions and states in Nigeria were included and the EAs stratified into rural and urban localities with the primary respondents being all female members of the household 15-49 years of age during the time of the survey.

\subsection{Data Source}

The relevant information on child mortality is derived from full birth histories collected from selected women of reproductive age. The analysis is restricted to children born in the 5-year period prior the survey. The analysis was based on the recoded children data which consist of 31,482 births. Details concerning sample design and procedures of data collection can be found in the 2013 NDHS report (NPC, 2014).

\subsection{Study Variables}

Infant/child survival status (whether a child is dead or alive) was the outcome variable in this study. Selection of the predictor variables was based on several previous studies - for example, (Curtis et al., 2000; Houle et al., 2013; Olufunke \& Obafemi, 2011; Mosley \& Chen, 1984; UNICEF, 2015; NPC, 2014) as well as consideration of variables included in the NDHS. The explanatory variables were grouped into three levels - child, mother and household characteristics.

Child-level variables (U); sex of child, child is twin, birth order, size of child, prenatal care, assistance during child's delivery, birth interval, number of antenatal visits, tetanus injection and breastfeeding.

Mother-level variables (V): maternal education, maternal occupation, religion, ethnicity, age at first birth, marital status, husband's education and husband's age.

Household/community-level variables (X): source of drinking water, type of toilet facility, type of cooking fuel, sex of household's head, wealth index, household has electricity, family size, children ever born and type of place of residence.

\subsection{Statistical Methodology}

Preliminary bivariate analysis was used to determine the nature and significance of association between survival status and each of the above predictor variables. Both the Pearson $\chi^{2}$ statistics and associated P-value were computed and used to determine level of significance of the association between a child's survival status and the predictor variables. Secondly, multiple logistic regression model to develop a predictive model for child survival and associated odds of dying given the set of significant predictors retained in the final model. The goodness of fit statistics for the final model was evaluated using proportion of cases correctly classified by the model as well as change in $\mathrm{R}^{2}$ statistics.

\subsection{Multiple Logistic Regression Model Used}

Let $Y$ be a binary outcome random variable with categories $Y=1$ (if child's death has occurred at the time of the survey) and $Y=0$ (if child is alive on day of survey) at the time of the survey. Let $\mathbf{z}=\left(Z_{1}, Z_{2} \ldots Z_{k}\right)$ be a vector of k-predictor variables of the response. Each $Z_{\mathrm{i}}$ can be a continuous random variable, or a 0-1 binary indicator variable. Then, the conditional probability that a given child has died given the vector of predictor variables $\mathbf{z}$ is given by $\pi=P(Y=1 \mid \mathbf{z})$. The logistic regression in the form:

$$
\log i t[\pi]=\ln \left(\frac{\pi}{1-\pi}\right)=\beta_{0}+\beta_{1} Z_{1}+\beta_{2} Z_{2}+\ldots+\beta_{k} Z_{k}+\varepsilon
$$

Where, $\varepsilon=$ the error term, $\beta=$ coefficient of $Z_{\mathrm{i}} \mathrm{i}=1,2 \ldots, \mathrm{k}$

$\pi=$ Probability that a child been within 5 years of the survey and having the background etharacteristics specified by $\mathbf{z}$ was dead before the survey date, $1-\pi=$ Probability that child was still alive while $1-\pi=$ odds of child being dead to log-odds of no infant/child dead.

The study used 4 models in the analysis:

Child-level (Model 1)

$$
\operatorname{Pr}[Y=1 \mid(U)]=\frac{\exp \left(\alpha^{\prime} U\right)}{1+\exp \left(\alpha^{\prime} U\right)}
$$


Mother-level (Model 2)

$$
\operatorname{Pr}[Y=1 \mid(V)]=\frac{\exp \left(\beta^{\prime} V\right)}{1+\exp \left(\beta^{\prime} V\right)}
$$

Household-level (Model 3)

$$
\operatorname{Pr}[Y=1 \mid(X)]=\frac{\exp \left(\gamma^{\prime} X\right)}{1+\exp \left(\gamma^{\prime} X\right)}
$$

Full model (Model 4)

$$
\operatorname{Pr}[Y=1 \mid(U, V, X)]=\frac{\exp \left(\alpha^{\prime} U+\beta^{\prime} V+\gamma^{\prime} X\right)}{\left[1+\exp \left(\alpha^{\prime} U+\beta^{\prime} V+\gamma^{\prime} X\right)\right]}
$$

\subsection{Data Analysis}

Analysis in this study was based on the survival status of the 31,482 children within first 5 years of their life.

To determine the magnitude of deaths, distribution of deaths and the total number of births by survival determinants at the child, mother and the household-level characteristics was done as presented in Table 1 and 2. Bivariate analyses were done with the use of $\chi^{2}$ test to determine the significant association between child's survival status and the predictor variables. At the multivariate level of analysis, the logistic model was used to predict the survival status from the predictor variables (Tables 3 to 6 ).

For a child who had died it was felt that the memory of the mother of the exact age of death was unreliable. Thus, the fact that the child had died was recorded, which generated a binary data consisting of only 2 possible observations, dead or alive. We considered the relationship between the probability of a positive response (i.e. had died) and the explanatory variables. This is a non-linear relationship since the probability must lie between 0 and 1 and a linear function would violate this condition. We linearize this relationship by applying logit transformation which is:

$$
\operatorname{Logit}(p)=\ln \left(\frac{p}{1-p}\right)=\alpha+\beta_{1} U+\beta_{2} V+\beta_{3} X
$$

Where U, V, X are the Child, Mother and Household-level variables respectively. Here, the underlying distribution is a logistic distribution.

To estimate the parameters, Maximum Likelihood Estimation approach was used. For each trial we assume there is a probability $\mathrm{P}$ of a positive response. The distribution of $\mathrm{R}$ is binomial with parameters $\mathrm{N}$ and $\mathrm{P}$. Thus, for a choice of parameters $\alpha$ and $\beta_{i}$ we compute the corresponding P of each of age group and hence the probability of obtaining the observed values of R. This is the Likelihood of the data. The "best" choice of $\alpha$ and $\beta_{i}$ is taken to be the values that make the Likelihood a maximum.

Table 1. Distribution of deaths and the total number of births by survival determinants - (child-level characteristics)

\begin{tabular}{llll}
\hline Variable & \% of deaths & Child is dead & N(Total) \\
\hline Sex of child & & & \\
Male & 9.9 & 1,578 & 15,965 \\
Female & 8.4 & 1,308 & 15,517 \\
\hline Child is twin & & & \\
No & 8.6 & 2,610 & 30,384 \\
Yes & 25.1 & 276 & 1,098 \\
\hline Birth order & & & \\
1st order & 9.5 & 581 & 6,109 \\
2nd-3rd order & 7.9 & 791 & 10,074 \\
$\geq 4^{\text {th }}$ order & 9.9 & 1,514 & 15,299 \\
\hline
\end{tabular}




\begin{tabular}{|c|c|c|c|}
\hline \multicolumn{4}{|l|}{ Size of child } \\
\hline Large & 7.4 & 1,012 & 13,589 \\
\hline Average & 8.7 & 1,110 & 12,689 \\
\hline Small & 12.8 & 611 & 4,756 \\
\hline \multicolumn{4}{|l|}{ Prenatal care by } \\
\hline Not attended & 15.1 & 1,732 & 11,456 \\
\hline Unskilled Worker & 7.0 & 544 & 7,760 \\
\hline Skilled Worker & 5.0 & 610 & 12,266 \\
\hline \multicolumn{4}{|l|}{ Delivery assisted by } \\
\hline Not assisted & 35.3 & 150 & 425 \\
\hline Unskilled Worker & 10.1 & 1,930 & 19,027 \\
\hline Skilled Worker & 6.7 & 806 & 12,030 \\
\hline \multicolumn{4}{|l|}{ Birth interval } \\
\hline$<24$ months & 13.8 & 803 & 5,817 \\
\hline 24-47 months & 8.0 & 1,194 & 14,904 \\
\hline $48+$ months & 6.2 & 282 & 4,580 \\
\hline \multicolumn{4}{|l|}{ Antenatal visits } \\
\hline No visit & 12.0 & 2,223 & 18,492 \\
\hline Inadequate & 5.8 & 145 & 2,483 \\
\hline Adequate & 4.9 & 518 & 10,507 \\
\hline \multicolumn{4}{|l|}{ Tetanus injection } \\
\hline No injection & 11.8 & 2,274 & 19,307 \\
\hline Received injection & 5.0 & 612 & 1,2175 \\
\hline \multicolumn{4}{|l|}{ Place of delivery } \\
\hline Home & 10.6 & 2,108 & 19,770 \\
\hline Hospital & 6.8 & 778 & 11,512 \\
\hline \multicolumn{4}{|l|}{ Breastfeeding } \\
\hline Never breastfed & 40.6 & 670 & 1,649 \\
\hline Ever breastfed & 7.4 & 2,216 & 29,833 \\
\hline
\end{tabular}

Table 2. Distribution of deaths and the total number of births by survival determinants -(mother-level characteristics)

\begin{tabular}{llll}
\hline Variable & \% of deaths & Child is dead & N(Total) \\
\hline Maternal occupation & & & \\
No & 9.3 & 895 & 9,649 \\
Yes & 9.1 & 1,984 & 21,697 \\
\hline Religion & & & \\
Christian & 7.6 & 956 & 12,654 \\
Islam & 10.3 & 1,887 & 18,354 \\
Other & 9.6 & 30 & 314 \\
\hline
\end{tabular}




\begin{tabular}{llll}
\hline Ethnicity & 11.2 & 1,402 & 12,517 \\
Hausa/Fulani & 8.6 & 295 & 3,414 \\
Igbo & 6.1 & 209 & 3,442 \\
Yoruba & 8.0 & 973 & 12,054 \\
Other & & & \\
\hline Age at 1 st birth & 10.2 & 1,912 & 18,665 \\
$12-19$ years & 7.6 & 916 & 12,009 \\
$20-29$ years & 7.2 & 58 & 808 \\
$30-45$ years & & & 604 \\
\hline Marital status & 8.9 & 54 & 29,990 \\
Not married & 9.1 & 2,726 & 888 \\
Currently married & 11.9 & 106 & 12,507 \\
Formerly married & & & 5,985 \\
\hline Husband's education & 11.4 & 1,424 & 9,009 \\
No education & 9.6 & 577 & 3,981 \\
Primary & 7.4 & 664 & 3,148 \\
Secondary & 5.6 & 221 & 11,729 \\
Higher & & & 9,748 \\
\hline Husband's age & 9.0 & 307 & 4,816 \\
16-29 years & 8.3 & 969 & \\
$30-39$ years & 9.4 & 916 & \\
$40-49$ years & 10.5 & 511 & \\
$50-95$ years & & & \\
\hline
\end{tabular}

Table 3. Distribution of deaths and the total number of births by survival determinants -(household/community-level characteristics)

\begin{tabular}{llll}
\hline Variable & \% of deaths & Child is dead & N(Total) \\
\hline Source of drinking water & & & 17,133 \\
Improved & 8.4 & 1,437 & 14,349 \\
Unimproved & 10.1 & 1,447 & 15,151 \\
\hline Type of toilet facility & 8.1 & 1,230 & 16,331 \\
Improved & 10.1 & 1,656 & 510 \\
Unimproved & & & 30,972 \\
\hline Type of cooking fuel & 4.9 & 25 & 28,133 \\
Clean & 9.2 & 2,861 & 3,349 \\
Unclean & & & \\
\hline Sex of household head & 9.3 & 2,607 & 7,076 \\
Male & 8.3 & 279 & 7,386 \\
Female & & & \\
\hline Wealth index & 11.8 & 835 & 887 \\
Poorest & 12 & & \\
Poorer & &
\end{tabular}




\begin{tabular}{llll}
\hline Middle & 8 & 502 & 6,272 \\
Richer & 7.1 & 412 & 5,806 \\
Richest & 5.1 & 250 & 4,942 \\
\hline Has electricity & & & 16,856 \\
No & 10.8 & 1,814 & 14,577 \\
Yes & 7.3 & 1,066 & 7,567 \\
\hline Family size & & & 12,787 \\
$1-4$ members & 12.4 & 940 & 11,128 \\
$5-7$ members & 8.1 & 1,013 & \\
$8+$ members & 8.2 & 915 & 9,002 \\
\hline Children ever born & & & 9,588 \\
$1-2$ children & 7.4 & 668 & 12,892 \\
3-4 children & 8.3 & 798 & 4,614 \\
$5+$ children & 11.0 & 1,420 & 6,517 \\
\hline Region & & & 9,906 \\
North Central & 7.1 & 328 & 2,816 \\
North East & 10.1 & 661 & 3,747 \\
North West & 11.6 & 1,146 & 3,882 \\
South East & 9.3 & 263 & 10,351 \\
South South & 6.6 & 249 & 21,131 \\
South West & 6.2 & 239 & \\
\hline Place of residence & & 666 & \\
Urban & 6.4 & & \\
Rural & 10.5 & 220 & \\
\hline
\end{tabular}

Table 4. Child-level (model 1)

\begin{tabular}{llll}
\hline Variable & Odds ratio & P-value & C.I. \\
\hline Sex of child & & & \\
Male (0) & 1.00 & & \\
Female (1) & 0.83 & 0.00 & $(0.76,0.91)$ \\
\hline Child is twin & & & \\
No (0) & 1.00 & & \\
Yes (1) & 2.71 & 0.00 & $(2.28,3.23)$ \\
\hline Birth order & & & \\
$1^{\text {st }}$ order (0) & 1.00 & 0.0 & $(0.97,3.33)$ \\
$2^{\text {nd }}-3^{r d}$ order (1) & 1.80 & 0.06 & $(1.22,4.28)$ \\
$\geq 4^{\text {th }}$ order (2) & 2.29 & 0.01 & \\
\hline Delivery assisted by & & & $(0.61,1.83)$ \\
Not assisted (0) & 1.00 & 0.40 & $(0.79,2.50)$ \\
Unskilled worker (1) & 1.06 & 0.84 & \\
Skilled worker (2) & 1.40 & 0.25 & \\
\hline
\end{tabular}




\begin{tabular}{llll}
\hline Size of child & & & \\
Large (0) & 1.00 & 0.00 & $(1.34,1.73)$ \\
Average (1) & 1.52 & 0.00 & $(1.22,1.57)$ \\
Small (2) & 1.38 & 0.00 & \\
\hline Prenatal care & & & \\
Not attended (0) & 1.00 & 0.00 & $(0.39,1.17)$ \\
Unskilled worker (1) & 0.68 & 0.00 & $(0.63,0.80)$ \\
Skilled Worker (2) & 0.71 & 0.00 & \\
\hline Birth interval & & & $(0.43,0.58)$ \\
$<24$ months (0) & 1.00 & & $(1.72,2.35)$ \\
24-47 months (1) & 0.50 & 0.00 & \\
$48+$ months (2) & 0.80 & 0.002 & $(0.13,0.17)$ \\
\hline Breastfeeding & & & \\
Never breastfed (0) & 1.00 & 0.00 & $(0.76,1.31)$ \\
Ever breastfed (1) & 0.15 & 0.00 & $(0.82,1.32)$ \\
\hline Antenatal visits & & & \\
No visit & 1.00 & 0.89 & \\
Inadequate visits & 1.00 & 0.98 & \\
Adequate visits & 1.05 & 0.65 & \\
\hline Tetanus injection & & 0.62 & \\
No injection & 1.00 & 0.67 & \\
Received injection & 0.95 & & \\
Constant & 0.88 & & \\
\hline
\end{tabular}

Table 5. Mother-level (model 2)

\begin{tabular}{llll}
\hline Variables & Odds ratio & P-value & C.I. \\
\hline Maternal education & & & \\
No education (0) & 1.00 & 0.002 & \\
Primary (1) & 0.54 & 0.00 & $(0.41,0.71)$ \\
Secondary (2) & 0.59 & 0.00 & $(0.45,0.76)$ \\
Higher (3) & 0.78 & 0.05 & $(0.61,1.004)$ \\
\hline Maternal occupation & & & \\
Not working & 1.00 & 0.00 & \\
Working (1) & 1.10 & 0.04 & $(1.004,1.20)$ \\
\hline Religion & & & \\
Christian (0) & 1.00 & 0.83 & $(0.61,1.33)$ \\
Islam (1) & 0.90 & 0.59 & $(0.62,1.37)$ \\
Other (2) & 0.92 & 0.69 & \\
\hline Ethnicity & & & \\
Hausa/Fulani (0) & 1.00 & 0.00 & $(0.76,0.95)$ \\
Igbo (1) & 0.85 & 0.004 & $(0.68,0.92)$ \\
Yoruba (2) & 0.79 & 0.002 &
\end{tabular}




\begin{tabular}{llll}
\hline Other (3) & 1.09 & 0.33 & $(0.92,1.28)$ \\
\hline Age at 1st birth & 1.00 & 0.02 & $(0.73,1.27)$ \\
$12-19$ years (0) & 0.96 & 0.78 & $(0.82,1.44)$ \\
$20-29$ years (1) & 1.09 & 0.56 & $(0.60,1.71)$ \\
$30-45$ years (2) & & 0.002 & $(1.16,1.76)$ \\
\hline Marital status & 1.00 & 0.97 & $(0.57,0.81)$ \\
Not married (0) & 1.009 & 0.001 & $(0.62,0.89)$ \\
Currently married (1) & 1.43 & & $(0.72,1.00)$ \\
Formerly married (2) & & 0.00 & \\
\hline Husband education & 1.00 & 0.00 & $(0.89,1.93)$ \\
No education (0) & 0.68 & 0.001 & \\
Primary (1) & 0.75 & 0.05 & \\
Secondary (2) & 0.85 & 0.17 & \\
Higher (3) & 1.31 & 0.00 & \\
\hline Husband occupation & 17.32 & & \\
Not working (0) & & & \\
Working (1) & 1.00 & & \\
Constant & 1.31 & \\
\hline
\end{tabular}

Table 6. Household-level (model 3)

\begin{tabular}{|c|c|c|c|}
\hline Variable & Odds ratio & P-value & C.I. \\
\hline \multicolumn{4}{|c|}{ Sex of household head } \\
\hline Male (0) & 1.00 & & \\
\hline Female (1) & 1.19 & 0.02 & $(1.03,1.37)$ \\
\hline \multicolumn{4}{|l|}{ Place of residence } \\
\hline Urban (0) & 1.00 & & \\
\hline Rural (1) & 1.37 & 0.00 & $(1.23,1.53)$ \\
\hline \multicolumn{4}{|l|}{ Wealth index } \\
\hline Poorest (0) & 1.00 & 0.00 & \\
\hline Poorer (1) & 0.93 & 0.16 & $(0.83,0.03)$ \\
\hline Middle (2) & 1.22 & 0.006 & $(1.06,1.41)$ \\
\hline Richer (3) & 1.24 & 0.019 & $(1.04,1.49)$ \\
\hline Richest (4) & 1.51 & 0.001 & $(1.20,1.90)$ \\
\hline \multicolumn{4}{|l|}{ Has electricity } \\
\hline Yes $(0)$ & 1.00 & & \\
\hline No (1) & 1.14 & 0.008 & $(1.03,1.26)$ \\
\hline \multicolumn{4}{|l|}{ Family size } \\
\hline $8+$ members $(0)$ & 1.00 & 0.00 & \\
\hline 5-7 members (1) & 2.78 & 0.00 & $(2.48,3.11)$ \\
\hline 1-4 members (2) & 3.49 & 0.00 & $(3.09,3.95)$ \\
\hline
\end{tabular}




\begin{tabular}{llll}
\hline Children ever born & & & \\
$5+$ children (0) & 1.00 & 0.00 & $(0.51,0.64)$ \\
$3-4$ children (1) & 0.58 & 0.00 & $(0.33,0.42)$ \\
1 -2 children (2) & 0.38 & 0.00 & \\
\hline Place of delivery & & & \\
Hospital (0) & 1.00 & 0.02 & $(1.10,1.36)$ \\
Home (1) & 1.22 & 0.00 & \\
\hline Source of water & & & $(0.89,1.05)$ \\
Unimproved (0) & 1.00 & & \\
Improved (1) & 0.96 & 0.37 & $(0.83,0.99)$ \\
\hline Type of toilet & & & \\
Unimproved (0) & 1.00 & 0.00 & $(0.63,1.44)$ \\
Improved (1) & 0.91 & 0.03 & \\
\hline Cooking fuel & & & $(0.86,1.24)$ \\
Unclean (0) & 1.00 & & \\
Clean (1) & 0.95 & 0.83 & $(0.56,0.74)$ \\
\hline Region & & & \\
North-central (0) & 1.00 & $0.50,0.71)$ \\
North-east (1) & 0.74 & 0.00 & \\
North-west (2) & 0.64 & 0.00 & \\
South-east (3) & 0.60 & 0.00 & \\
South-south (4) & 1.10 & 0.28 & \\
South-west (5) & 1.03 & 9.37 & \\
Constant & & 0.00 & \\
\hline
\end{tabular}

\section{Results}

\subsection{Association between Infant and Child Survival Status and the Individual Level (Child and Mother) Characteristics}

Table 1 and 2 shows that infant/child mortality was highest among male children (9.9\%), children with multiple birth $(25.1 \%)$, children who were of the $4^{\text {th }}$ birth order and above $(9.9 \%)$, children who were small in size at birth $(12.8 \%)$, children whose mother did not go for prenatal care during their pregnancies $(15.1 \%)$ and those whose mother were not assisted during delivery (35.3\%), whose birth interval was less than 24 months (13.8\%), children of mothers with no antenatal visits $(12.0 \%)$ children whose mother did not receive tetanus injection during pregnancies $(11.8 \%)$, children whose deliveries were at home $(10.6 \%)$ and children who were never breastfed $(40.6 \%)$.

At the mother-level, infant/child mortality was highest among children whose mothers had no former education $(11.2 \%)$, children whose mothers were not working $(9.3 \%)$, children of Muslim mothers (10.3\%), children of Hausa/Fulani mothers $(11.2 \%)$, children of teenage mothers $(10.2 \%)$, children whose mothers were formerly married (11.9\%), children of illiterate fathers (11.4\%) and children of aged fathers (10.5\%).

\subsection{Association Between Infant and Child Survival Status and the Household/Community Level Characteristics}

Table (1.2) shows that infant and child mortality was highest among children in the households with unimproved source of drinking water $(10.1 \%)$, toilet facility was unimproved $(10.1 \%)$ and the type of cooking fuel was unclean $(9.2 \%)$. It was higher among children in households headed by men $(9.3 \%)$ and in a community where there was no electric connection (10.8\%). It was highest among children in households with small family size (12.4\%), households with large number of children $(11.0 \%)$ and in households with poorest wealth index $(11.8 \%)$. It was highest among children of mothers who lived in North-west (11.6\%) and among those whose mothers lived in rural 
areas (10.5\%).

\subsection{Child-level, Mother-level and Community-level Characteristics}

At the multivariate level of analysis, as shown in Tables 3 to 6, 4 models were generated.

Table 3 shows that the risk of death was significantly associated with child's gender, multiple birth, birth order, size of child at birth, prenatal care, birth interval and breastfeeding $(P<0.05)$. Nevertheless, there is variation in infant and child deaths within these risk factors. For instance, female children had less risk of early childhood mortality compared with male children. The odds of experiencing early childhood mortality was 1.80 for children of birth order between $2^{\text {nd }}$ and $3^{\text {rd }}$ and 2.29 times greater for those of the $4^{\text {th }}$ order and above as opposed to children of $1^{\text {th }}$ order.

The results showed that health seeking behaviour had a significant influence on infant/child survival. Children of mothers who used prenatal care services and who were attended to by health workers during deliveries were less likely to die young compared with children whose mothers did not attend prenatal care and were not attended to by health workers during deliveries. Children who were average in size at birth were $52 \%$ more likely of early childhood mortality while those who were small at birth were $38 \%$ more likely compared with children who were large at birth. The odds ratio showed that infant/child with birth intervals more than 24 months had less risks of early childhood mortality compared with those whose preceding birth intervals were less than 2 years. Infant and Child who were ever breastfed were $85 \%$ less likely of early childhood mortality compared with who were never breastfed.

\subsection{Mother-Level Characteristics}

Table 4 shows that maternal education, maternal occupation, ethnicity, marital status and husband education had significant relationship with infant and child mortality. However, there are differences in infant and child deaths within the factors at mother level. The study found that education had an impact on infant and child survival. The likelihood of experiencing infant/child mortality was lower among children of educated mothers and fathers than the children whose parents had no former education. Odds of mortality among the children of mothers that had primary, secondary and higher education reduced by $46 \%, 41 \%$ and $22 \%$ respectively compared to children of mothers with no education. In the same vein, odds of death among the children whose fathers had primary, secondary and higher education reduced by $32 \%, 25 \%$ and $15 \%$ respectively compared to children whose fathers had no formal education. Risks of early childhood deaths were less among children of Igbo and Yoruba ethnic groups but higher among children of other minority ethnic groups compared with children of Hausa/Fulani mothers. Risks of infant/child death were less among children whose mothers were between the age of 20-29 years at the time of their birth but higher among the children of aged mothers compared with children who were born by teenage mothers. The study showed that age at first birth was strongly important in infant and child survival.

\subsection{Household/Community-Level Characteristics}

Table 5 shows that the sex of household head, place of residence, wealth index, electricity, family size, number of children ever born, place of delivery, toilet facility and region had important association with infant and child mortality. The odds ratio show that children of household headed by women were $19 \%$ more likely to experience infant and child mortality compared with children of the household headed by men. The likelihood of infant/child mortality among the children of mothers who lived in rural areas increased by $37 \%$ compared to children of urban dwelling mothers while odds of infant/child mortality among children of mothers in the middle, richer and richest wealth index increased by $22 \%, 24 \%$ and $51 \%$ respectively compared to children of mothers of poorest wealth index. Having electricity has been shown to have impact on infant/child mortality. Odds of infant/child mortality increased by $14 \%$ in households without electric connection compared to ones with electricity. Health seeking behaviour was found to have an impact on infant/child survival; odds of infant/child mortality among children of mothers who had their deliveries in the hospital reduced by $22 \%$ compared to children of mothers whose deliveries were at homes.

Family size was found to have negative association with infant/child mortality. The likelihood of infant/child mortality in children from families with 5-7 members increased by $178 \%$ and $249 \%$ for children from families with 1-2 members compared to children from families with more than 8 members. Whereas, number of children in the family had a positive association with infant and child death (the lower the number of children in the family, the lower the death experience).

Sanitation was shown to be significantly associated with infant/child mortality. Unimproved source of drinking water, bad toilet facility and unclean type of cooking fuel were found to have positive association with infant/child mortality. Household with unimproved source of drinking water increased odds of infant/child mortality by $4 \%$ 
compared with homes with improved source of drinking water. Households with unimproved type of toilet facilities increased odds of infant/child mortality by $9 \%$ compared to those with improved toilet facilities. Similarly, living in households that were using unclean cooking fuel increased odds of infant/child mortality by $5 \%$ compared to those using clean type.

Infant/child mortality also varied from region to region. The odds of experiencing infant/child mortality was higher among children from the north-central compared to children from north-east, north-west and south-east. Contrary to expectation, the risks of infant/child deaths are higher among children from south-south and south-west compared with children from north-central of the country.

\subsection{Full Model}

Table for full model is not shown because its size and its similarity to tables 2 to 5 . However, results from the table shows that sex of child, multiple birth, birth order, size of child, prenatal care, birth interval, breastfeeding, maternal education, maternal occupation, maternal current age, marital status, husband age, age at first birth, sex of household, place of residence, family size, number of children ever born and region have significant relationship with infant and child mortality in models 1, 2, 3 and/or 4. For instance, in model 1,

The odds ratio show that female child had slightly higher risk of infant/child mortality compared with male child. The odds of having infant/child mortality is 1.87 times greater for children with single births as opposed to those with multiple birth. The odds of experiencing infant/child mortality is $3 \%$ less for children of birth order between $2^{\text {nd }}$ and $3^{\text {rd }}$ and $25 \%$ higher compared to children of the $4^{\text {th }}$ order and above. Children who were large at birth are $29 \%$ and those who were average in size are $39 \%$ more likely of infant/child mortality compared with children who were small at birth. The first 3 results were contrary to what were expected. This showed confounding effects of some important risk factors which were neglected by most of the previous researchers. Good medical care, sanitation and breastfeeding when accounted for might make some risk factors less significant. Children whose mothers were educated were less likely to die during infancy and childhood compared with those children whose mothers were not educated. Children with birth intervals more than 24 months had less risks of infant/child mortality compared with those of first births. Infant/child whose mothers were not working were $14 \%$ more likely to die young compared with those children whose mothers were working. Children who were breastfed by their mothers had lower risk of mortality than their counterpart who were never breastfed. Infant/child of married mothers were less likely to die compared to those children whose mothers were either not married or formerly married. Children of young fathers (16-29 years) were more likely to die during infancy and childhood compared with the children of older fathers. Father's age was found to be negatively associated with infant and child mortality (the higher the age, the lower the likelihood of deaths). Infant and child mortality also varied from region to region.

\section{Discussion of Results}

This study has addressed two specific objectives. First, it examined the magnitude or extent of infant and child mortality in Nigeria. Second, it identified and examined the effects of individual (child and mother), household and community-level characteristics on the risk of dying in infancy and childhood in Nigeria. The study developed a new empirical conceptualization of under-five mortality research by considering mortality at infancy and childhood separately and comparing determinants of mortality simultaneously at 3 levels (individual (child and mother), household and community) in Nigeria, using 2013 NDHS data, the most recent national survey. The study has attempted to control for the effects of potential confounders by including many factors in the analyses without over modelling.

The descriptive tabulations of the association between infant and child survival status and the sample characteristics at the 3 levels revealed the magnitudes of infant and child mortality in Nigeria. At child-level, infant and child mortality was highest among children with multiple birth, male children, children who were of the $4^{\text {th }}$ birth order and above, children whose mothers did not go for prenatal care during their pregnancies, those whose mothers were not assisted during deliveries, children whose mothers did not receive tetanus injection during pregnancies, children whose deliveries were at home and children who were never breastfed.

At the mother-level, infant and child mortality was highest among children whose mothers had no former education, children whose mothers were not working, children who were born by Muslim mothers, children of mothers who belonged to the Hausa/Fulani ethnic group, children who were born by teenage mothers, children whose mothers were formerly married, children whose fathers were illiterates and those whose fathers were very old.

Finally, at the household/community-level, infant and child mortality was highest among children of women who 
lived in the households where the source of drinking water was unimproved, children of women who lived in households where toilet facility was unimproved and children of mothers in the households where the type of cooking fuel was unclean. It was higher in the households headed by women and in a community where there was no electric connection. It was equally highest in households with small family size, in households with large number of children and in households with poorest wealth index. It was highest among children of women who lived in the north-west of Nigeria and among children of women who lived in rural areas.

The implication of these results is that much still needs to be done by the national and state governments of Nigeria if considerable reduction in infant and child mortality will be achieved.

The study identified individual-level factors, such as child's sex, multiple births, birth order, birth interval, child's size at birth, breastfeeding, number of antenatal visits, antitetanus injection received, vaccination, assistance during delivery, prenatal care, diarrhea treatment, fever/cough treatment, maternal education, age of mother at $1^{s t}$ birth, maternal current age, ethnicity, religion affiliation, husband education and husband age as significant determinants of both infant and child mortality in Nigeria. At household/community level, source of drinking water, type of toilet facility, type of cooking fuel, wealth index, household has electricity, family size, number of children ever born, region and the type of residence were identified as significant risk factors. As previously disclosed, most of these factors remained significantly associated with infant and child mortality even after adjusting for the effects of other significant factors, although some to a smaller degree.

Considering a child's sex, as pointed out earlier, the results of multivariate analysis confirmed this as an important predictor of infant and child mortality. Previous studies suggest that globally, death rates of males generally exceed those of females (Sawyer, 2012). Sawyer (Sawyer, 2012) found that infant girls have a biological advantage in survival over infant boys. This pattern of survival agrees with another study by Kazembe et al. Kazembe et al. (2012), which showed that the association between child mortality and sex is diverse across countries in Africa and this was found by this study to be similar to regions in Nigeria. The current study established higher mortality risks for male children than for females in Nigeria.

This study also shows that children of mothers that started childbearing at an early age were more prone to experience infant and child mortality more than those that commenced at an older age. Younger mothers formerly received supports from relatives that will stay with them for a long period of time but due to the economic crisis, this is no more a usual practice, so teenage mothers must take care of their children by themselves. This relationship did not contradict what prior studies have reported (Palloni et al., 1994).

Birth interval was another important determinant of infant and child mortality. It has negative association with infant/child mortality. As child interval increased, the likelihood of infant and child mortality reduced. This result was consistent with other previous studies ("houle2013household", n.d.-a), (“demographic2014health", n.d.-e). Plausible justification for this is that mothers that waited for more than 24 months before having the next pregnancy would have regained most body nutrients and blood loss during last pregnancy and breastfeeding.

Another significant determinant of infant and child mortality was birth order. It has a linear relationship with infant/child mortality. The likelihood of infant and child mortality increased with increased child's birth order. This is consistent with other previous studies (Antai, 2011), (Lawoyin, 2001). Possible reason for this is that as birth order increases, competition for foods and other inadequate resources essential for child survival will increase in the household. Also, as birth order increases level of child care reduces since the mother will have more children to care for. Children of lower order birth are more likely to survive compared to the children of higher order birth.

This study also found that children that were small at birth were more likely to die especially during infancy than those that were having normal birth size. Possible explanations for this, are the effects of premature births. Most premature children are more prone to have sepsis which is one of the leading causes of deaths at early stage of life. Other complications of premature births are infant jaundice, cessation of breathing etc. Earnest and early intervention such as the promotion of breastfeeding is recommended for very small and stunted children, particularly during infancy (Black et al., 2013). This is consistent with other previous studies (Palloni et al., 1994), (Bailey, 1989).

This study has also shown that children raised in urban areas were more likely to survive better than those in rural areas. This finding supported what have been reported in other previous studies (Antai, 2011, Lawoyin, 2011). Likely reason for this is that children in urban areas have access to better health care facilities and all other vital health related services which are necessary for their survival.

This study established that maternal education is an important determinant of infant and child mortality. It found that maternal education was most important for child survival, both in infancy and childhood. A possible 
explanation for this as noted by Mosley and Chen (Mosley \& Chen, 1984) was that the level of education of a mother can affect child survival in determining her choices and increasing her knowledge in health care practices that has to do with treatment of diseases, nutrition, hygiene, contraceptive use and preventive care. Palloni (Palloni et al., 1994) noted that it is expected that women with secondary education, compared to less educated women, should have a better knowledge of the modern world and be able to use it to the survival advantage of their children. According to Caldwell (Curtis et al.2000), a mother's education enables her to adequately use the facilities of the city even if she lives in a village. For example, she is more concerned about the health conditions of her child, more capable of receiving attention from hospital workers and more knowledgeable about where the right facilities are and how best to use them to her child's advantage.

Further, ethnicity was found in this study as an important variable, which affects infant and child mortality in Nigeria. Moreover, previous studies have established the relationship between ethnicity and health outcomes in Nigeria (Antai, 2011), (Olufunke \& Obafemi, 2011). Outcome of this study revealed that the Yoruba ethnic group had the lowest risks of infant and child mortality, followed by the Igbo, while the Hausa/Fulani had the highest risks of infant and child mortality in Nigeria. Some of the possible reasons for these ethnic variations in infant and child mortality include differences in educational attainment and health-seeking practices (Adedini et al. 2014), (Antai, 2011). The Hausa/Fulani have the highest risks of infant and child mortality, perhaps because they are mostly less educated, as found in this study. Other reasons that could be attributed to higher infant and child mortality risks among these ethnic groups are poor health-seeking behaviour as well as early marriage which might lead to early childbearing (Wall, 1998).

It was found in this study that the risks of infant and child mortality were significantly lower if children are raised in households that had electric connection, drinkable water and a flush toilet. Sastry (Sastry, 1997) noted that drinking water, access to health services and toilet facilities are important determinants of child health outcomes, with the health problem becoming more serious for children of uneducated women who equally lack access to such household amenities. This study also revealed that when significant covariates such as wealth status and maternal education were adjusted for, the significance of these household facilities reduced to a lesser degree. This implies that the significance of access to drinkable water, electric connection, good toilet facility and clean type of fuel tends to be trivial for children of educated and mothers of high economic status while the effect is significant for the children of less-educated and poorer mothers. Effect of drinking water and toilet facility on infant and child mortality is consistent with certain previous studies. According to (NPC, 2014), better sanitation facility reduces morbidity and mortality, adequate sanitation facilities, at the household level, include an improved toilet and a method of disposal that separates waste from human contact.

Wealth index is another important determinant of infant and child mortality that was found in this study, which showed an inverse association between family wealth and infant and child mortality. Children from households in poor wealth quintile are likely to suffer from lack of basic facilities due to limited access to household resources. This study found that children of mothers with improved wealth status have less risks of infant and child death, both in urban and rural areas. This confirms the significance of household wealth as a strong determinant of infant and child mortality.

Furthermore, findings from this study showed that region was significantly associated with infant and child mortality in Nigeria. Comparing the risks of infant and child death in the northern regions with that of the southern regions of the country, generally the former had higher risks of infant and child death compared to the latter. Comparing the risks of death in the 6 regions, the north-east and north-west, both in northern Nigeria, are the two regions with the highest risks of infant and child mortality. The north-central region, which is also in the northern part of the country, had a far lower risk of infant and child death than the rest of the regions in the north. A possible explanation is that while the other two regions of the north are made up of states predominantly occupied by Hausa and Fulani ethnic groups, the north-central region is majorly occupied by the minority ethnic groups. Besides, the nation's Federal Capital Territory (FCT) is in the north-central and has brought a lot of development to this region. Such development is expected to have a positive effect on infant and child survival, possibly through regular immunization campaigns, improved access to health care facility, better attitude towards health seeking and improved quality of life among the people through increased access to economic opportunities and resources.

While the characteristics at the community level tend to reduce infant and child mortality in some regions, those community characteristics tend to aggravate risks of mortality in some others. Results of this study suggest that the former scenario represents the situation in the southern regions of the country while the latter scenario represents the situation in the north-east and north-west. Other reasons for regional variations in infant and child mortality across regions in Nigeria are diverse. For instance, north-east and north-west regions are regions where children 
were mostly of higher order birth - i.e. fifth order or higher, mothers were mostly uneducated, mainly unemployed and in poor households, and were mostly teenagers at the time of their first birth (Adedini et al., 2014).

The current study found place of residence as an important determinant of infant and child mortality in Nigeria. The result showed that children of mothers living in rural areas had significantly higher risks of infant and child mortality compared to children of mothers in the urban areas. Possible reason for this is because access to good health care services is likely to be insufficient in rural areas compared to urban areas. Besides, mothers from the rural areas are likely to be less educated compared with their counterparts in the urban areas.

Adjusting for the effects of other important factors made the effect of place of residence on children survival to be statistically insignificant. This suggests that certain variables, such as maternal education, access to drinkable water in the community, access to healthcare services by members of the community could lead to reduction in the risks of infant and child mortality even in rural areas.

This study has established that health care contexts are important predictors of infant and child mortality in Nigeria. It was found that living in communities that had a high percentage of mothers who delivered their children in hospital was associated with lower risks of infant and child mortality. Moreover, residence in communities with a high percentage of mothers who had prenatal care by skilled medical workers was associated with lower risks of infant and child mortality. These findings suggest that children born or raised in communities where the uptake of prenatal care services and hospital delivery is high had higher survival chances, perhaps because of good health care contexts provided by the availability of health facilities and skilled birth attendants within such communities.

\section{Conclusions}

This study answered two essential research questions:

i) What is the magnitude of infant and child mortality in Nigeria?

ii) What is the individual, household, and community-level factors associated with infant and child mortality in Nigeria?

These research questions were answered by addressing the two specific objectives of the study.

\section{Competing Interests Statement}

The authors declare that there are no competing or potential conflicts of interest.

\section{References}

Antai, D. (2011). Regional inequalities in under-5 mortality in Nigeria: a population-based analysis of individual-and community-level determinants. Population Health Metrics, 9(1), 6. https://doi.org/10.1186/1478-7954-9-6

Bailey, M. (1989). Individual and environmental influence on infant and child mortality in rural Sierra Leone: a multivariate analysis. Ren Kou Xu Kan, 12, 155-185.

Black, R. E., Victora, C. G., Walker, S. P., Bhutta, Z. A., Christian, P., De Onis, M., ... \& Uauy, R. (2013). Maternal and child undernutrition and overweight in low-income and middle-income countries. The lancet, 382(9890), 427-451. https://doi.org/10.1016/S0140-6736 (13)60937-X

Caldwell, J. C. (1979). Education as a factor in mortality decline an examination of Nigerian data. Population studies, 395-413. https://doi.org/10.2307/2173888

Feyisetan, B. J. (1985). Environmental sanitation and infant mortality: a study of relationships in ile-ife, Nigeria. Studies in Third World Societies, (34), 235-263.

Kayode, G. A., Adekanmbi, V. T., \& Uthman, O. A. (2012). Risk factors and a predictive model for under-five mortality in Nigeria: evidence from Nigeria demographic and health survey. BMC pregnancy and childbirth, 12(1), 10. https://doi.org/10.1186/1471-2393-12-10

Kazembe, L., Clarke, A., \& Kandala, N.-B. (2012). Childhood mortality in sub-Saharan Africa: cross-sectional insight into small-scale geographical inequalities from census data. BMJ open, 2(5), e001421. https://doi.org/10.1136/bmjopen-2012-001421

King, G., \& Zeng, L. (2001). Improving forecasts of state failure. World Politics, 53(4), 623-658. https://doi.org/10.1353/wp.2001.0018

Lawoyin, T. (2001). Risk factors for infant mortality in a rural community in Nigeria. The journal of the Royal Society for the Promotion of Health, 121(2), 114-118. https://doi.org/10.1177/146642400112100213 
Mosley, W. H., \& Chen, L. C. (1984). An analytical framework for the study of child survival in developing countries. Population and development review, 10, 25-45. https://doi.org/10.2307/2807954

Palloni, A., Pinto Aguirre, G., \& Lastiri, S. (1994). The effects of breast-feeding and the pace of childbearing on early childhood mortality in Mexico.

Sastry, N. (1997). What explains rural-urban differentials in child mortality in Brazil? Social science \& medicine, 44(7), 989-1002. https://doi.org/10.1016/S0277-9536 (96)00224-9

Sawyer, C. C. (2012). Child mortality estimation: estimating sex differences in childhood mortality since the 1970s. PLoS Medicine, 9(8), e1001287. https://doi.org/10.1371/journal.pmed.1001287

Taylor, M. (2017). Infant mortality among African American women compared to European American women in New York City.

UNICEF. (2012). Progress report on committing to child survival: A promise renewed. New York, NY: Author.

UNICEF. (2015). Committing to child survival: A promise renewed: Progress report 2015. UNICEF.

Wall, L. L. (1998). Dead mothers and injured wives: the social context of maternal morbidity and mortality among the Hausa of northern Nigeria. Studies in family planning, 341-359. https://doi.org/10.2307/172248

\section{Copyrights}

Copyright for this article is retained by the author(s), with first publication rights granted to the journal.

This is an open-access article distributed under the terms and conditions of the Creative Commons Attribution license (http://creativecommons.org/licenses/by/4.0/). 